\title{
Analysis of Bridge Player Profiles According to Their Intelligence Areas
}

\author{
Fatma Pervin Bilir ${ }^{1}$, Yeliz Sirin ${ }^{2}$ \\ ${ }^{1}$ University of Çukurova of Physical Education and Sports High School of Department of Sports Management, Physical \\ Education and Sport, Turkey \\ ${ }^{2}$ University of Kahramanmaraş Sütçü İmam of Physical Education and Sports High School, Physical Education and \\ Sport, Turkey \\ Correspondence: Yeliz Sirin, University of Kahramanmaraş Sütçü İmam of Physical Education and Sports High School, \\ Physical Education and Sport, Turkey.
}

Received: July 5, $2017 \quad$ Accepted: August 7, $2017 \quad$ Online Published: August 8, 2017

doi:10.11114/jets.v5i9.2526 URL: https://doi.org/10.11114/jets.v5i9.2526

\begin{abstract}
The aim of this study is to figure out profiles of bridge players and analyzing them according to their intelligence areas. The sample of the study is consist of 100 volunteers out of 200 bridge players who have attended "Çukurova open double bridge championship" in Adana, Turkey at February 2016. Data have been collected via "Personal Information Form" and "Multiple Intelligence Areas Assessment Scale" developed by Gülşen (2015). Data have been analyzed not only via descriptive statistics but also Mann Whitney $\mathrm{U}$ test was used for double comparison and Kruskal Wallis $\mathrm{H}$ test for multiple comparison. The profile of the players contributed to the study is; $30 \%$ women, $70 \%$ men, $25 \%$ of the population is between 51 and 60 years age, $67 \%$ is married, $71 \%$ has bachelor degree, $57 \%$ is working for government sector and $33 \%$ for private sector. Most of the players are working as teacher, engineer, or medical doctor and $50 \%$ of the population is performing a physical activity like walking, football and basketball. It is found that players' internal intelligence area is the highest among all intelligence areas; additionally the lowest one is found as the rhythmic intelligence. It is determined that the players' from different business sectors have significant differences among internal, analytic, interpersonal, physical/kinesthetic intelligence areas, and significant difference is determined for the physical/kinesthetic intelligence among the players who perform physical activities and who do not.
\end{abstract}

Keywords: bridge, multiple intelligence areas, physical activity, physical/kinesthetic intelligence

\section{Introduction}

Bridge is a sport branch with Olympic competitions and in Turkey, its activities are realized through the organizations of Bridge Federation. Games like bridge, chess and go, which are called mind sports, are skill games in which mental factors are more dominant than physical elements (Federico, Gabriele, and Capelli (2014)). Bridge is defined as a mind sport since it plays a role in gaining mental habits. Mental habits enable developing different solutions to newly encountered problems (Cuoco et al., 1996). In the sport of bridge, which is played in teams of at least two people, it is important to research into how the opponents play and to train before the competitions, to build love and respect between a well-matched team and athletes, just like the other sport branches. As a strategic game which develops analytic thinking that requires thinking with the partner, it includes high excitement at every stage. Bridge is a mental sport that is loved by great masses in the whole world and it is pleasant both to play it and to watch it (Yaykin, 2011). When the historical process of bridge is analyzed, the card game that was fashionable among English noblemen in the 17th century is stated to be derived from Whist. It is believed that Whist turned into one of the first forms of Bridge in Turkey at the end of the 19th century. World championships which used bridge team variations with couples started in 1950. The World Bridge Federation was established in Oslo, Norway on 18 August 1958. Bridge Federation was established in Turkey in 1987. When the literature on bridge was examined, the following studies on bridge players were reached. Dreber et al. (2011) examined the effect of dopamine and risk choices on bridge tournament players and the results showed that dopamine system played an important role on individual differences related with risk taking. In Federico, Gabriele, and Capelli (2014) study about the diets and drug use of bridge tournament players, it was found that about one third of the players were older than 60 and $77 \%$ had one of the diseases such as cardiovascular disease, back/joint problems, insomnia, asthma and diabetes. $60 \%$ of the players were found to use at least one drug, including substances in the list of banned drugs by World Anti-Doping Agency and 44\% were found to have an extra diet. 
Mukaetova and Lawton (1999) were found to have a study on a 70-year-old acute psychosis patient playing bridge on the computer. No studies have been found on the multiple intelligences of bridge players. When studies about mind sports and athletes were examined, although studies were found in literature about chess athletes (Bilalic \& Gobet, 2007), no national studies have been found in literature.

Intelligence, which was expressed with cognitive processes until 1950s, is also expressed with affective and emotional processes today, which brought up the idea that people can be intelligent in different areas. Based on this thought, arguments have focused on the idea that different abilities can be the product of intelligence. The most influential and comprehensive study on this issue was conducted by Howard and Gardner (1999). When Gardner came up with the "theory of Multiple Intelligences" in his book "frames of mind" published in 1983, first of all he introduced the presence of seven intelligences, later in his work "intelligences reframed", he mentioned the presence of an "eighth" intelligence and added another dimension of intelligence (Gardner, 1999). Gardner defines intelligence as the capacity of a person to create products that are valued by one or more than one culture, the ability to create effective and efficient solutions to problems encountered in real life and the ability to discover new and complicated problems. The theory of Multiple Intelligences brought down the understanding of traditional IQ (Intelligent Quotient) and instead brought the understanding of an intelligence that favors and values the individual. That is, individuals are no longer considered as intelligent based on "verbal/linguistic" or "logical/mathematical" intelligences; on the contrary, individuals are assessed as multi-dimensional (Baş, 2011). According to Gardner (1997), each child is born having different intelligences and they can develop in those areas with experiences. Each individual can be more developed in one or more than one field of intelligence. Gardner (2006) stated that just as inheritance influences the development of these intelligence areas, the environment is also a supportive and inhibiting factor. The resources that the individual has, the cultural values of the society he/he lives in, geographical conditions, the state that the family is in and the state that the individual is in have an influence on the development of intelligence areas. Armstrong stated that different cultures are resources of the development of different intelligence areas (Armstrong, 2008). Unlike the classical theory, the theory of intelligence suggests that each person can have abilities in all intelligence areas and teaching arrangements should be made to develop these. Thus, when the literature is analyzed, studies which have associated students' ways of learning and success with the theory of multiple intelligences can be seen (Yılmaz \& Fer, 2003; Çelen, 2006; Bozkurt \& Aydoğdu, 2009; Demir, 2010; Baş, 2011). Areas of intelligence put forward by Gardner which can be developed with experiences and which exists in different rates in all individuals consist of eight areas:

Verbal/Linguistic Intelligence; expresses the ability of an individual to use words effectively orally or in writing (Gürel\& Tat 2010), to use concepts, grammar and syntax of a language (Gardner, 1999), and behaviors such as writing newspaper, novel, story, poem, article, report, letter, giving a speech in front of people, talking to people around, listening to them and understanding the intentions of people and what they say (Lazear, 1999).

Logical/Mathematical Intelligence; expresses an individual's ability to make mathematical operations and to think logically (Gürel\& Tat, 2010), to distinguish between logical or numerical patterns and to reason (Saban, 2005)

Musical/Rhythmic Intelligence; is the ability to understand and use rhythm, tone, melody and harmony (Gürel and Tat 2010:349), to comprehend and distinguish musically, to think about, to transform and to express the reason of an event musically (Saban, 2009).

Visual/Spatial Intelligence; is the ability to perceive the visual-spatial world accurately and to make conversions with these perceptions (Armstrong, 2008). It includes an individual's ability to observe, perceive and assess his environment objectively, and to show the visual and spatial ideas he gets from the environment graphically (Saban, 2005).

Social/Interpersonal Intelligence; is the ability to perceive, understand and distinguish other people's feelings and motivations (Gürel and Tat 2010:349; Armstrong, 2008:7). People whose social/interpersonal intelligence is developed learn through interaction and they are successful in making oral or non-oral communication with people (Gardner, 2006).

Bodily/Kinesthetic Intelligence; is an individual's use of his body to express his ideas and feelings and his hands to produce things (Kuru, 2001). It expresses showing expertise in using the whole body to express ideas and feelings and developed abilities of coordination, balance, strength and flexibility (Armstrong, 2008).

Nature Intelligence; is the ability to know innumerable living beings in nature (Armstrong, 2008), understanding and associating things in nature, understanding, realizing and explaining the balance and symbols of nature (Saban, 2009).

Intrapersonal Intelligence; symbolizes an individual's ability to understand his own feelings, thoughts, preferences and interests and to act accordingly (Gürel\&Tat 2010). It expresses the ability to act based on an individual's own knowledge (Armstrong, 2008). 
Gardner (2006) stated that there is an association between individual's mental processes and their outstanding intelligence, the individual's dominant intelligence type influences the process of learning and thinking and the individual's learning style can be developed according to his outstanding type of intelligence. In tests developed in line with the theory of Multiple Intelligences, weak and developed intelligence types are found and specific solutions for the individual are presented (Gürel \& Tat, 2010). Gardner (2006) stated that applying the theory of Multiple Intelligences to employees would be useful for people, teams and institutions with a multifaceted environment. At the same time, when sport branches are taken into consideration, athletes' sports types can be accepted as an environmental factor that influences the development of their intelligence areas. Until recently, sport was perceived as only the training of the body and its cognitive and affective aspects were mostly ignored. The theory of Multiple Intelligences is a good model to analyze the areas that need to be improved in addition to being a guide for instruction (Armstrong, 2008). While there are studies on students in the field of sports, studies on the multiple intelligences of athletes are not enough in the literature. In his study on athletes doing individual and team sports, Tekin (2009) found that athletes doing individual sports had higher social and intrapersonal intelligences when compared with athletes doing team sports. In their study on students of sports, Kutz, Dyer, and Campbell (2013)found that bodily/kinesthetic intelligence and social intelligence were on the forefront. In a study which examined types of intelligence in terms of the branches of university students, Oral (2001) found that students of physical education and sports had high bodily/kinesthetic intelligence. In a study on students of school of sports, Çağlayan and Sezen (2007) found that the students had predominantly visual, bodily and auditory styles of learning. Kutz, Dyer, and Campbell (2013) analyzed the multiple intelligences areas of athletes who did periodical and non-periodical sports and found that the athletes who did periodical sports had predominantly existentialist and intrapersonal intelligence areas, while those who did non-periodical sports had predominantly visual intelligence. Ermiş, İmamoğlu, and Erilli (2012) found in their study that sports had a positive influence on the bodily and social intelligence scores of university students. In their study, Bayrak et al. (2005) found a significant difference between students who did sports and those who did not. In Güllü and Tekin's (2009) study, bodily intelligences of students of sport high school were found to be better than those of general high school students. Bavli (2013) examined the intelligence areas of students of sports management department in terms of their year of study and found that except naturalistic intelligence, students had similar intelligence scores in terms of their year of study. In Kemeç's (2016) study, differences were found between students of the school of physical education and sports in terms of their intelligences. In Ürgüp and Aslan's (2015) study, students of the school of physical education and sports were found to have higher social intelligences in general.

\subsection{Aim of the Study}

Our literature review did not reveal any studies about the multiple intelligences of bridge players. The purpose of this study is to present the profiles of bridge players in terms of the theory of multiple intelligences and the study contributes to literature about athletes of bridge.

Answers were sought to the following questions in this study:

- What are the demographic profiles of athletes who participate in the sport of bridge?

- How is the distribution of athletes of bridge in terms of their areas of multiple intelligences?

- Are there differences between areas of multiple intelligences in terms of gender?

- Are there differences between areas of multiple intelligences in terms of the sectors athletes were in?

- Are athletes of bridge interested in other sports?

- Are there differences between areas of multiple intelligences of athletes who do other sports and those who do not?

\section{Method}

\subsection{Participants}

This study is a descriptive quantitative study. The universe of the study consists of 200 athletes who participated in "Çukurova Open Couples Bridge Championship" held in Adana, Turkey in 2016, while the sample consisted of 100 athletes who participated voluntarily.

\subsection{Data Collection Tools and Data Analysis}

The data of the study were collected through "Personal Information Form" and "Multiple Intelligences Assessment Scale" developed by Gülşen (2015). "Multiple Intelligences Assessment Scale" consists of 10 sub-divisions and a total of 80 questions (Gülşen, 2015). In the 5-likert type scale, the items are scored as $0=A$ Absolutely inappropriate, $1=$ Slightly appropriate, 2=Partly appropriate, 3=Appropriate, $4=$ Absolutely appropriate. Total score intervals of intelligence areas were determined as 0-7= Not developed, 8-15=Somewhat developed, 16-23=Moderately developed, 
24-31=Developed, 32-40=Very developed. In the data analysis, descriptive statistics were used such as percentage, frequency, arithmetic mean and standard deviation. It is found that data do not have a homogeneous distribution and non-parametric tests were used for fundamental statistics. Due to non-parametric distribution, Mann-Whitney U Test was used for paired comparisons and Kruskal Wallis H Test was used for multiple comparisons. Cronbach's Alpha $(\alpha)$ value of the whole scale, which is a measure of internal consistency, that is, how closely related a set of items are as a group, was determined as 0,87 .

\section{Findings}

Table 1. Descriptive statistics related to demographical information of the participants

\begin{tabular}{|c|c|c|c|c|c|}
\hline Variables & $\mathrm{f}$ & $\%$ & Variables & $\mathrm{F}$ & $\%$ \\
\hline Gender & & & Educational status & & \\
\hline Woman & 30 & 30.0 & Primary school & 1 & 1.0 \\
\hline Male & 70 & 70.0 & High school & 10 & 10.0 \\
\hline Marital Status & & & University & 71 & 71.0 \\
\hline Married & 67 & 67.0 & Graduate & 18 & 18.0 \\
\hline Single & 33 & 33.0 & Success Status & & \\
\hline Age & & & No Success & 74 & 74.0 \\
\hline$<30$ & 16 & 16.0 & National & 24 & 24.0 \\
\hline $31-40$ & 24 & 24.0 & International & 1 & 1.0 \\
\hline $41-50$ & 15 & 15.0 & National and International & 1 & 1.0 \\
\hline $51-60$ & 25 & 25.0 & Year License & & \\
\hline $61-70$ & 16 & 16.0 & 5 ve alt 1 & 45 & 45.0 \\
\hline 70> & 4 & 4.0 & $6-10$ & 19 & 19.0 \\
\hline Institution Employed & & & $11-15$ & 14 & 14.0 \\
\hline Not working & 10 & 10.0 & $16-20$ & 10 & 10.0 \\
\hline Private sector & 33 & 33.0 & $21-25$ & 4 & 4.0 \\
\hline Public Institution & 57 & 57.0 & $26-30$ & 3 & 3.0 \\
\hline
\end{tabular}

Table 1 shows that the athletes; $30 \%$ woman, $70^{\prime} \%$ male and about $67 \%$ were married, $33 \%$ were single. Athletes between the ages of 31 and 65 years. It is observed that the maximum age interval is 25\% 51-60 and the minimum age interval is $4 \%$ to 70 and over. In terms of the variable of occupation, $57 \%$ were working in public sector, $33 \%$ were working in private sector, $10 \%$ currently does not work in any institution and $24 \%$ of the athletes have national success. The athletes are $45 \%$ licensed athletes. It was determined that $47 \%$ of the athletes were from Adana, $20 \%$ from Mersin, $7 \%$ from Ankara and 6\% from Ankara came from Istanbul to participate in the tournament.

Table 2. Average Scores of Athletes in terms of their intelligence areas

\begin{tabular}{lllrrc}
\hline Areas of Intelligence & $\mathrm{N}$ & $\overline{\mathbf{X}}$ & \multicolumn{1}{l}{ ss } & \multicolumn{1}{c}{ Min. } & \multicolumn{1}{l}{ Max. } \\
\hline Verbal/Linguistic & 100 & 29.81 & 6.20 & 13.00 & 49.00 \\
Logical/Mathematical & 100 & 29.76 & 9.51 & 4.00 & 80.00 \\
Visual/Spatial & 100 & 26.09 & 7.93 & 12.00 & 71.00 \\
Musical/rhythmic & 100 & 25.11 & 8.64 & 8.00 & 40.00 \\
Naturalistic & 100 & 29.36 & 8.09 & 11.00 & 41.00 \\
Interpersonal & 100 & 30.31 & 5.80 & 17.00 & 40.00 \\
Bodily/Kinesthetic & 100 & 26.23 & 6.88 & 0.00 & 40.00 \\
Intrapersonal & 100 & 31.00 & 6.27 & 1.00 & 74.00 \\
\hline
\end{tabular}

When Table 2 is analyzed, it can be seen that the highest average values of athletes belonged to intrapersonal intelligence (31.00), while the lowest belonged to musical intelligence (25.11). Since the average values in all areas corresponded to the interval of "appropriate" according to multiple intelligences assessment scale, the athletes were found to have "developed intelligence level".

Mann-Whitney U Test was used to analyze whether there were differences in the intelligence scores of athletes in terms of gender and the results were given in Table 3. 
Table 3. Athletes' Intelligences in terms of Gender

\begin{tabular}{llllll}
\hline Intelligences & Gender & $\mathrm{N}$ & Mean rank & $\mathrm{Z}$ & $\mathrm{p}$ \\
\hline \multirow{2}{*}{ Logical/Mathematical } & Women & 30 & 33.77 & & \\
Naturalistic & Men & 70 & 57.67 & -3.782 & $\mathbf{. 0 0 0 * *}$ \\
& Women & 30 & 60.13 & & \\
& Men & 70 & 46.37 & -2.182 & $\mathbf{. 0 2 9 *}$ \\
\hline
\end{tabular}

$* p<0.05 * * ; p<0.01$

Significant differences were found between women and men in terms of athletes' logical and naturalistic intelligence areas. Mean ranks of men were found to be higher in logical intelligence, while the mean ranks of women were found to be higher in naturalistic intelligence.

One of the questions in the study was the question of whether there were differences in the scores of athletes in terms of the sectors they worked in. The results of this question were given in Table 4.

Table 4. Athletes' Intelligences in terms of the sector they work in Institution

\begin{tabular}{|c|c|c|c|c|c|}
\hline Intelligences & Institution & $\mathrm{N}$ & Mean rank & Chi-Square & $\mathrm{p}$ \\
\hline \multirow{3}{*}{ Intrapersonal } & Unemployed & 10 & 51.35 & \multirow{3}{*}{6,919} & \multirow{3}{*}{$.031 *$} \\
\hline & Private Sector & 33 & 60.94 & & \\
\hline & Public Sector & 57 & 44.31 & & \\
\hline \multirow{3}{*}{ Verbal } & Unemployed & 10 & 57.30 & \multirow{3}{*}{2,547} & \multirow{3}{*}{.280} \\
\hline & Private Sector & 33 & 55.32 & & \\
\hline & Public Sector & 57 & 46.52 & & \\
\hline \multirow{3}{*}{ Logical } & Unemployed & 10 & 38.70 & \multirow{3}{*}{9.662} & \multirow{3}{*}{$.008 * *$} \\
\hline & Private Sector & 33 & 63.03 & & \\
\hline & Public Sector & 57 & 45.32 & & \\
\hline \multirow{3}{*}{ Visual } & Unemployed & 10 & 45.40 & \multirow{3}{*}{3.818} & \multirow{3}{*}{.148} \\
\hline & Private Sector & 33 & 58.55 & & \\
\hline & Public Sector & 57 & 46.74 & & \\
\hline \multirow{3}{*}{ Musical } & Unemployed & 10 & 49.00 & \multirow{3}{*}{5.899} & \multirow{3}{*}{.052} \\
\hline & Private Sector & 33 & 60.39 & & \\
\hline & Public Sector & 57 & 45.04 & & \\
\hline \multirow{3}{*}{ Naturalistic } & Unemployed & 10 & 44.90 & \multirow{3}{*}{0.572} & \multirow{3}{*}{.751} \\
\hline & Private Sector & 33 & 49.55 & & \\
\hline & Public Sector & 57 & 52.04 & & \\
\hline \multirow{3}{*}{ Interpersonal } & Unemployed & 10 & 35.70 & \multirow{3}{*}{15.132} & \multirow{3}{*}{$.001 * *$} \\
\hline & Private Sector & 33 & 66.17 & & \\
\hline & Public Sector & 57 & 44.03 & & \\
\hline \multirow{3}{*}{ Bodily } & Unemployed & 10 & 54.15 & \multirow{3}{*}{8.072} & \multirow{3}{*}{$.018^{*}$} \\
\hline & Private Sector & 33 & 61.36 & & \\
\hline & Public Sector & 57 & 43.57 & & \\
\hline
\end{tabular}

$* p<0.05 * * ; p<0.01$

According to Table 4, the results of the analysis between the variable of athletes' sector and their intelligences showed significant differences in the areas of intrapersonal, logical, interpersonal and bodily intelligences. When all the intelligences were considered, except for the area of naturalistic intelligence, the mean ranks of athletes working in private sector are higher in all areas of intelligences.

The athletes' states of being interested in another sport were analyzed and the distributions were given in Table 5 . 
Table 5. Other sports that the athletes are interested in

\begin{tabular}{llllll}
\hline Sport branches & f & \% & Sport branches & f & \% \\
\hline Basketball & 5 & 5.0 & Running & 4 & 4.0 \\
Snooker & 1 & 1.0 & Table tennis & 2 & 2.0 \\
Cycling & 1 & 1.0 & Pilates & 3 & 3.0 \\
Mountain climbing & 1 & 1.0 & Tennis & 3 & 3.0 \\
Fitness & 4 & 4.0 & Volleyball & 1 & 1.0 \\
Football & 8 & 8.0 & Yoga & 1 & 1.0 \\
Wrestling & 1 & 1.0 & Walking & 9 & 9.0 \\
& & & Swimming & 6 & 6.0
\end{tabular}

When Table 5 was analyzed, it was found that half of the athletes were recreatively interested in other sports branches besides bridge. The groups with majority were found to be groups walking with $9 \%$ and groups playing football with $8 \%$.

Differences were found between the bodily intelligence scores of the athletes who did other sports and those who did not based on the analysis results which are shown in Table 6.

Table 6. Bodily/Kinesthetic Intelligences of Athletes who do sports recreatively and those who do not

\begin{tabular}{|c|c|c|c|c|c|}
\hline Intelligence & Other sports & $\mathbf{N}$ & Mean rank & $\mathbf{Z}$ & $\mathbf{p}$ \\
\hline & Yes & 50 & 58.74 & -2.846 & \\
\hline Bodily/Kinesthetic & No & 50 & 42.26 & & $.004 * *$ \\
\hline
\end{tabular}

According to Table 6, Mann-Whitney U Test, which was conducted to find out whether there were differences between the intelligences of athletes who did other sports and those who did not, differences were found in bodily intelligence scores. When the mean ranks are analyzed, it can be seen that the bodily intelligence averages of athletes who did sports (58.74) were found to be higher than those who did not (42.26).

\section{Discussion and Conclusion}

The fundamental philosophy of the theory of multiple intelligences is that everybody has all the intelligences; however, profiles are different, and each of these intelligences should be brought out and assessed in their own environments. Multiple intelligence areas should be developed by creating appropriate learning environment and doing appropriate activities (Altan, 2011). The purpose of this study is to analyze the profiles of athletes playing bridge in terms of the theory of multiple intelligences

According to the demographic findings of the study, the profiles of bridge players showed that they are mostly male, middle aged, married, university graduates with an undergraduate degree of 5 years and less, employees working in public sector and doing physical activity.

The results of the study showed that multiple intelligence scores of bridge players are "developed intelligence level" in all areas of intelligence. When the ages and educational status of bridge players were analyzed, it was found that the youngest age was 30 with the highest age interval over 50 years of age and most of the players were found to be university graduates. When studies about bridge were reviewed, the ages of the athletes are in parallel with these results. The "developed intelligence level" of the athletes can be explained with the effectiveness of their experiences and learning so far. The researchers' hypothesis that logical intelligence would be the highest intelligence was not supported by the results, and the highest intelligences were ranked as intrapersonal, social, verbal and logical intelligence, respectively. When the characteristics of intrapersonal intelligence such as the individual's ability to act based on his own knowledge (Armstrong, 2008) and concentration, intellectuality, metacognition, mood, high level thinking skills and reasoning (Lazear, 2000) are considered, it can be said that they are in parallel with the characteristics that bridge players should have. The most important characteristic of sport is allowing people to interact and socialize. Social intelligence being the second in rank can be due to the fact that athletes learn through interaction and that they are successful in communicating verbally or nonverbally with people (Gardner, 2006). When the literature was reviewed, in studies conducted with athletes and students, high areas of intelligence were intrapersonal, social, logical and bodily intelligences (Kemeç, 2016; Aslan, Dalkıran, and Özer (2015), 2015; Ürgüp \& Aslan, 2015; Kul, 2015; Ermiş, İmamoğlu, and Erilli (2012); Güllü \& Tekin 2009; Tekin, 2009; Tekin et al., 2008; Jones, 2006). 
When the athletes' intelligences were analyzed in terms of their gender, significant differences were found between female and male athletes in logical and naturalistic intelligences. Male athletes were found to have higher values in logical intelligence, while female athletes were found to have higher values in naturalistic intelligence. In terms of biological characteristics, these results can be in parallel with general sexist understanding. Tekin (2009) found that men had higher logical intelligence than women. In Kemeç's (2016) study, verbal, visual and musical intelligences were higher in women, while logical intelligence was higher in men. In Ermiş, İmamoğlu, and Erilli (2012), social intelligence was found to be higher in women. In a study by Bavlı (2013) on sport management students with regard to their year of study, it was found that except naturalistic intelligence, students had similar intelligence scores in terms of their year of study.

Another question answered by the study was the intelligences of athletes in terms of the sector they worked in. When all the intelligences were considered, intelligences except for naturalistic intelligence had high values, although the values were not very different from each other. Intrapersonal, logical, social and bodily intelligences of athletes working in private sector were significantly different than those of athletes working in public institutions or unemployed athletes. The athletes working in private sector had higher values. The results of private sector and these results can be said to correspond.

The perception in our study about bridge players that they do not move and just play cards at the table is widespread. The results of our study show that half of the athletes creatively walk, play football and basketball, swim, do fitness, run, play tennis, do Pilates, play table tennis, volleyball and snooker, go mountain climbing, wrestle, ride bicycle, play volleyball and do yoga, respectively, according to the results of the study. In addition, the results of the study show that the athletes interested in this sport have lower bodily intelligence when compared with those who are not. In literature, significant differences were found in studies conducted on individuals who do sports and those who do not in terms of their intelligences. Kemec, (2016); Kul, (2015); Kutz, Dyer, and Campbell (2013); Tekin et al., (2008); Bayrak, Çeliksoy, and Çeliksoy(2005) are in parallel with the results of our study.

When the results of the study are analyzed, it can be seen that bridge players have a developed intelligence, high intrapersonal intelligence, with high naturalistic intelligence in women, high logical intelligence in men, with high intrapersonal, logical, social and bodily intelligences of those working in private sector and with higher bodily intelligences in individuals who do sports.

Being interested in other sports besides the sport of bridge causes positive developments in terms of physical activity. In fact, just like the energy spent during physical activities, energy is spent for operating mental processes while playing bridge. However, physical development cannot be ensured by playing bridge, exercises including physical activity are obligatory for this. In order for athletes of bridge to advance their bodily intelligences, special physical activity programs are recommended to be implemented for all athletes or athletes should be directed or encouraged to these areas. In addition, for future studies, researchers can be recommended to comparatively analyze the multiple intelligences of athletes of bridge and athletes from other sports branches.

\section{References}

Altan, M. Z. (2011). The theory of multiple intelligences and values education. Journal of Education and Teaching, 1(4), 53-57. https://doi.org/10.14527/C1S4M6

Armstrong, T. (2008). Multiple intelligences in theclassroom. 3rd Edition, Alexandria, VA: ASCD.

Aslan, C. S., Dalkıran, O., \& Özer, U. (2015). Investigation of athletes' multiple intelligence domains doing cyclic and acyclic sports: a pilot study. Journal of Contemporary Educational Studies (IntJCES), 1, 26-33

Baş, G. (2011). The reflection of multiple intelligence theory on learning teaching processes. Education in Science and Intelligence, S. 138-139, Ağostos-Eylül, 14-28.

Bav, Ö. (2013). Investigation the multiple intelligence areas of sport management students. International Journal of Sport Studies, 3(4), 379-382.

Bayrak, Ç., Çeliksoy, M. A., \& Çeliksoy, S. (2005). Intelligence related to physical education and sports school students in view of multiple intelligences theory and applied talent relationship between entrance examination.4th National Physical Education and Sports Teacher Symposium, Bursa/Turkey.

Bilalic, M., McLeod, P., \& Gobet, F. (2007). Personality profiles of young chess players. Personality and Individual Differences, 42, 901-910. https://doi.org/10.1016/j.paid.2006.08.025

Çağlayan, H. S., \& Sezen, M. (2007). Investigating the learning modality of school of physical education and sport students, Gazi Journal of Physical Education and Sports Sciences, 12(4), 35-48.

Çelen, A. (2006). The effects of the multiple intelligences theory activities on the achievements of student's cognitive, 
affective and psychomotor domains at the physical education lesson. (Master's Thesis). Abant İzzet Baysal University, Bolu, Turkey.

Cuoco, A., Goldenberg, E. P., \& Mark, J. (1996). Habits of mind: An organizing principle for a mathematics curriculum. Journal of Mathematical Behavior, 15(4), 375-402. https://doi.org/10.1016/S0732-3123(96)90023-1

Dreber, A., Rand, D. G., Wernerfelt, N., Garcia, J. R., Vilar, M. G., Lum, J. K., \& Zeckhauser, R. (2011). Dopamine and risk choices in different domains: Findings among serious tournament bridge players. J Risk Uncertain, 43, 19-38. https://doi.org/10.1007/s11166-011-9119-z

Ermiş, E., İmamoğlu, O., \& Erilli, N. A. (2012). The effect of sports on the bodily-kinesthetics and interpersonal multiple intelligences scores of university students. Journal of Sports and Performance Researches, 3(2), 23-29.

Federico, B., Gabriele, P. W., \& Capelli, G. (2014). Use of medicines and dietary supplements among Bridge players in two world-class tournaments. Performance Enhancement \& Health, 3, 130-134. https://doi.org/10.1016/j.peh.2015.11.001

Gardner, H. (1997). Multiple intelligences as a partner in school improvement. Educational Leadership, 55(1), 20- 21.

Gardner, H. (1999). Intelligences Reframed: Multiple Intelligences for the 21st Century. New York: Basic Books.

Gardner, H. (2006). Multiple Intelligences: New Horizons. New York: Basic Books.

Güllü, M., \& Tekin, M. (2009). Comparison of multiple intelligence areas of students at sports high schools and public high schools. Niğde University Journal of Physical Education and Sport Sciences, 3(3), 247-258.

Gülşen C. (2015). Multiple intelligences areas evaluation scale developing study. International Journal of Human Sciences, 12(2), 1918-1930. https://doi.org/10.14687/ijhs.v12i2.3469

Gürel, E., \& Tat, M. (2010). Multiple intelligence theory: From unitary intelligence conception to multiple intelligence approach. The Journal of International Social Research, 3(11), 336-356.

History of Bridge. Retrieved from : http://www.bridgebum.com/bridge_history.php). Date of access: 25.04.2017.

Jones, M. K. (2006). Teaching of ballet: The application of multiple intelligence theory in ballet training: Dance alliance global assembly.

Kemec, D. G. (2016). Comparison of multiple intelligence fields of physical education and sports college students. Turkish Journal of Sport and Exercise, 18(1), 153-159. https://doi.org/10.15314/tjse.10358

Kul, M. (2015). Exploring the impact of sports participation on multiple intelligence development of high school female students. Educational Research and Reviews, 10(14), 2006-2011. https://doi.org/10.5897/ERR2015.2391

Kuru, E. (2001). Bodily/Kinesthetic intelligence and physical education. Gazi Üniversty Journal of Gazi Education Faculty, 21(2), 217-229.

Kutz, M., Dyer, S., \& Campbell, B. (2013). Multiple intelligence profiles of athletic training students. Internet Journal of Allied Health Sciences and Practice, 11(1), 1-9.

Lazear, D. (1999). The intelligence curriculum: Using MI to develop your students' full potential. Tucson, AZ: Zephyr Press.

Mukaetova, E. B., \& Lawton, L. C. (1999). The bridge player-a brief acute psychotic episode in an elderly man due to $\begin{array}{llllll}\text { playing computer } \quad \text { games. } \quad \text { J } & \text { Geriat. } & \text { Psychiatry, } & 14, & 1075-1079 .\end{array}$ https://doi.org/10.1002/(SICI)1099-1166(199912)14:12<1075::AID-GPS53>3.0.CO;2-X

Oral, B. (2001). An investigation of university students' intelligence as categories according to their fields of study. Education and Science, 26(122), 19-31.

Saban, A. (2005). Multiple intelligence theory and education. 5th Edition, Ankara: Nobel Publication Distribution.

Saban, A. (2009). Content analysis of Turkish studies about the multiple intelligences Theory. Educational Sciences: Theory \& Practice, 9(2), 859-876.

Tekin, M. (2009). Comparison of women-men sporty in terms of different intelligence level in individual and team sports' branches. Atabesbd, 11(4), 29-51.

Tekin, M., Filiz, K., Taşğın, Ö., \& Özmutlu, İ. (2008). Comparison of multiple intelligence areas of students who do and do not play in Secondary Education. Kafkas Üniversity Journal of Social Sciences Institute, 2, 1-10. Turkish Bridge Federation Retrieved from (http://www.tbricfed.org.tr/).

Ürgüp, S., \& Aslan, S. (2015). Investigation of students' multiple intelligence domains in three different departments of 
the school of physical education and sports. Educational Research and Reviews, 10(15), 2068-2075. https://doi.org/10.5897/ERR2015.2341

World Bridge Federation. Retrieved from: http://www.worldbridge.org/the-wbf/wbf-history/

Yaykın, E. (2011). Sorularda Briç. Retrieved from:http://www.tbricfed.org.tr/docs/sorularda_bric.pdf

Yllmaz, G., \& Fer, S. (2003). The Effects of Activities Based on the Multiple Intelligence Theory on Students' Academic Achievement and Retention Level. Hacettepe University Journal of Education, 25, 235-245.

\section{Copyrights}

Copyright for this article is retained by the author(s), with first publication rights granted to the journal.

This is an open-access article distributed under the terms and conditions of the Creative Commons Attribution license which permits unrestricted use, distribution, and reproduction in any medium, provided the original work is properly cited. 